\title{
Positive and negative outcomes of informal caregiving at home and in institutionalised long-term care: a cross-sectional study
}

Silke F. Metzelthin ${ }^{1 *}$ D, Ellen Verbakel ${ }^{2}$, Marja Y. Veenstra ${ }^{3}$, Job van Exel $^{4}$, Antonius W. Ambergen ${ }^{5}$ and Gertrudis I. J. M. Kempen ${ }^{1 *}$

\begin{abstract}
Background: Our ageing society is putting tremendous strain on public health and welfare programs to meet the needs of ageing individuals. Promoting informal caregiving is one way for policymakers to reduce this burden. However, caregiving may be experienced as stressful and is associated with adverse health consequences. While quite a lot of research focuses on caregiving for community-dwelling older adults, little is known about informal care in institutionalised long-term care (ILTC). Therefore, the objectives of this study were: 1) to compare characteristics of informal caregivers and care receivers and caregiver outcomes - at home and in ILTC; 2 ) to study the association between these characteristics and positive and negative caregiver outcomes; 3 ) to investigate the moderating effect of the setting (at home vs. ILTC) on these associations.

Methods: A cross-sectional study was conducted using the TOPICS-MDS DataSet. A total of 5197 Dutch dyads were included. The average age of the care receivers and caregivers was respectively 80.7 years and 63.2 years. Several sociodemographic, health-related and caregiving-related characteristics of care receiver and caregiver and two caregiver outcomes (i.e., subjective burden and care-related quality of life) were included in the analyses.

Results: Caregivers in both settings experienced comparable levels of subjective burden. Caregivers at home had slightly lower care-related quality of life than caregivers in ILTC. Several care receiver characteristics (i.e., male sex, married/cohabiting, more morbidities/disability, and less self-perceived health/psychological wellbeing) and several caregiver characteristics (i.e., female sex, being younger, living together with the care receiver, more objective burden, less self-perceived health, and more support) were associated with an increase in burden and/or a decrease in care-related quality of life. Some of these associations were stronger for dyads at home compared to dyads in ILTC.

Conclusions: Informal caregiving does not stop with admission to an ILTC facility. Both settings need an informal caregiving policy, which is (1) tailored to the individual characteristics of care receivers and caregivers; (2) pays attention to the identified risk groups; and (3) reduces the negative caregiver outcomes and emphasizes the positive outcomes at the same time.
\end{abstract}

Keywords: Informal caregiving, Family caregiving, Quality of life, Caregiving burden, Institutionalised long-term care, Community-dwelling older adults, Ageing in place, Home care

\footnotetext{
* Correspondence: s.metzelthin@maastrichtuniversity.nl;

g.kempen@maastrichtuniversity.nl

'Department of Health Services Research, Faculty of Health, Medicine and

Life Sciences, Care and Public Health Research Institute (CAPHRI), Maastricht

University, P.O. Box 616, 6200 MD Maastricht, Netherlands

Full list of author information is available at the end of the article
} 


\section{Background}

Like most Western countries, the Netherlands has to deal with an ageing society; the number of older adults ( $\geq 65$ years) will rise from 3 million in 2016 to 4.7 million in 2060 (http://www.cbs.nl). Also, with an ageing population, the demand for healthcare increases, while health care budgets and manpower lag behind [1]. Consequently, even in countries that currently have a large publicly funded health care sector, such as the Netherlands, informal care is becoming more and more important [2]. However, the positive effect of reducing professional care must be balanced with the potential negative effects of informal caregiving [3]. In view of demographic changes such as reduced fertility, a growing instability of couple relationships, increasing labour market flexibility and higher rates of female employment, the question arises whether sufficient informal caregivers will be available in the future and how long the available informal caregivers will be able to maintain their expanding caregiving tasks [3-5].

To engage, educate and support informal caregivers adequately, more knowledge is needed with regard to informal caregiving. More specifically, two aspects of informal caregiving are often neglected in research. First, while a substantial number of studies have been conducted regarding informal caregiving among community-dwelling older adults, little is known about informal care in institutionalised long-term care (ILTC) [6-8]. Contrary to what one might expect informal caregiving often continues after admission to an ILTC facility $[8,9]$; most informal caregivers make regular visits or even continue to perform care tasks such as personal care, managing money or buying groceries $[8,9]$. In addition, informal caregivers often take on new tasks such as involvement in the residents' council or communication with professional caregivers [8]. Second, irrespective of the setting, there is increasing evidence for the fact that informal caregiving may result in increased burden and subsequent negative health outcomes in caregivers [10]. However, informal caregivers may also experience positive aspects of care such as satisfaction, rewards, or enjoyment [11]. For example, in the study of de Boer et al. [12] only $7 \%$ of informal caregivers had no positive experiences in providing care. In addition, the study of Brouwer et al. [10] showed that half of the caregivers would become less happy, if somebody were to take over their caregiving tasks. Obviously, emphasizing the positive outcomes does not reduce the burden of informal caregiving directly, but a positive attitude regarding informal caregiving may positively influence the perception of care delivery [12-15], which may lead to improved health and wellbeing of both care receivers and caregivers and a more sustainable system of long-term care [9].

Consequently, the objectives of the current study were threefold: 1) to compare care receiver/caregiver characteristics and caregiver outcomes - at home and in ILTC; 2) to study the association between these characteristics and positive and negative caregiver outcomes (i.e., subjective burden and care-related quality of life) irrespective of the setting; and 3) to examine the moderating effect of the setting (at home vs. ILTC) on these associations.

\section{Methods}

\section{Design and participants}

For this cross-sectional study, we used The Older Persons and Informal Caregivers Survey Minimum DataSet (TOPICS-MDS; www.topics-mds.eu; [16]). TOPICSMDS comprises a set of standardised questionnaires for collecting information on the physical and mental health and wellbeing of older adults and their primary informal caregivers. The data were collected in more than 60 different studies between 2010 and 2013 as part of The National Care for the Elderly Program, commissioned by the Dutch Ministry of Health, Welfare and Sport. A selection of 25 studies was used for the present analyses, as they collected TOPICS-MDS in both older adults and their informal caregivers. The study design features, sampling framework and survey mode varied between projects (See Additional file 1). For the identification of informal caregivers, a definition was provided by the TOPICS-MDS research group, but the method used to identify informal caregivers varied (See Additional file 1). The number of dyads ranged from 10 to 926 dyads. The TOPICS-MDS was assessed in writing or during an interview (See Additional file 1). We selected older adults who lived at home $(n=4277)$ and those who lived in ILTC facilities $(n=920)$. In total, cross-sectional data of 5197 older adults and their primary informal caregiver was available.

\section{Measurements}

With regard to the care receiver characteristics, the following socio-demographic characteristics were taken into account: age, sex, ethnicity (i.e., native vs. non-native), educational level (i.e., low, middle, high), marital status (i.e., married/cohabiting vs. divorced/widowed/single), living situation (i.e., alone vs. with others). Furthermore, health-related characteristics were included in the analyses. First, multi-morbidity (17-item self-reported checklist) and disability (Katz-15; [17, 18]) of care receivers were included. Next, self-perceived health was assessed with the first question of the RAND-36 questionnaire [19] (i.e., 'How is your health in general?'). Finally, psychological wellbeing was measured with the 5-item subscale of the RAND-36 [19]. With regard to the caregiver characteristics, the following socio-demographic characteristics were included: age, sex, relationship with the care receiver (i.e., partner, child (in law), other) and whether the caregiver lived together with the care receiver (i.e., yes vs. no). 
Furthermore, health-related characteristics were included. Self-perceived health was measured using the same question as for the care receiver [19] (i.e., 'How is your health in general?'). Finally, caregiving-related characteristics were selected. More specifically, hours of informal caregiving were assessed by the question 'How many hours of informal care they had delivered during the last week regarding (a) tasks in or around the house of the care receiver (e.g., cleaning, preparing meals), (b) personal care of the care receiver (e.g., dressing or eating) and (c) assistance with other activities (e.g., travelling outside the house, visiting friends or doctors or taking care of financial matters)'. The number of hours was summed up with a theoretical maximum of $168 \mathrm{~h} /$ week [20]. Also, based on this question, the variation in caregiving tasks $(<2$ tasks vs. $\geq 2$ tasks) was calculated. Finally, hours of support from other non-professional caregivers or volunteers were taken into account.

Finally, two caregiver outcomes were included. First, subjective burden was assessed with the self-rated burden scale [21]. Informal caregivers were asked to indicate how burdensome they experience caring for the care receiver. The answers range theoretically from 0 (not at all straining) to 100 (much too straining). Second, the Carer-QoL7D [22] was used to measure seven dimensions of carerelated quality of life (i.e. care-related fulfilment, relational problems with the care recipient, mental health problems, physical health problems, problems completing daily activities, financial security and social support). The dimensions can be used to derive a care-related quality of life summary score. Informal caregivers could describe their personal situation by responding 'no,'some' or 'a lot of' for each dimension [23-25]. To generate a single summary score for the CarerQol-7D, the two positive items (carerelated fulfilment and social support) were reversed and a set of weights [26] was applied to each level of the seven dimensions. The CarerQol-7D summary score represents a utility score for the care situation that ranges theoretically between ' 0 ' (worst informal care situation) and 100 (best informal care situation).

More information about the TOPICS-MDS questionnaires can be found elsewhere (see Additional file 2).

\section{Statistical analysis}

First, two groups of dyads were created based on the living situation of the care receiver: a) care receiver at home (whether or not living together with the caregiver); and b) care receiver living in an ILTC facility (nursing home/home for the elderly). Subsequently, the groups of dyads were described and compared with regard to a) care receiver/caregiver characteristics; and b) caregiver outcomes (study objective 1) using descriptive statistics and bivariate statistics (i.e. chi square tests and independent t-tests). With regard to the second study objective, the associations between care receiver/caregiver characteristics and caregiver outcomes were evaluated applying mixed model multi-level analyses, as data were clustered within individual studies. The two outcomes 1) subjective burden and 2) care-related quality of life were included as dependent variables in separate models.

Finally, to investigate the moderating effect of the setting (at home vs. ILTC) on the associations between care receiver/caregiver characteristics and caregiver outcomes (study objective 3) an interaction term (independent variable $\mathrm{x}$ setting) was included in the analyses. Living at home was coded as 1 and living in ILTC was coded as 2 . Missing values were imputed by means of multiple imputations (except for categorical variables). To check for the robustness of the analyses, analyses were also conducted without imputation of missing values. For all statistical analyses the software package, SPSS for Windows, version 22.0, was used. An alpha level of .05 was considered as statistically significant.

\section{Results \\ Characteristics of care receivers and caregivers and caregiver outcomes}

Most characteristics of care receivers and caregivers and caregiver outcomes differed significantly between dyads at home and dyads in ILTC (see Table 1). Care receivers at home were younger and more often male than care receivers in ILTC facilities. Furthermore, they had better self-perceived health, fewer morbidities and lower levels of disability. However, psychological wellbeing was similar for the two groups of care receivers. Caregivers at home were mostly caring for either their parents or their partner. In contrast, ILTC caregivers were mostly caring for their parents and were consequently younger. The level of self-perceived health was significantly lower in caregivers at home compared to caregivers in ILTC. In addition, they delivered more caregiving hours than caregivers in ILTC, indicating a higher objective burden. Despite the higher level of objective burden at home, there was no significant difference between the groups with regard to caregivers' subjective burden. However, caregivers' care-related quality of life was significantly lower among caregivers caring for a care receiver at home compared to caregivers in ILTC.

\section{Associations between care receiver/caregiver characteristics and caregivers' subjective burden}

Informal caregivers experienced significantly more subjective burden, if the care receiver was male (40.736 vs. 38.641 ) and married/cohabiting (40.283 vs. 38.733 ). In addition, caregivers' subjective burden increased with more morbidities $(B=1.090)$ and higher levels of disability $(\beta=1.678)$ and decreased with better self-perceived 
Table 1 Care receiver/ caregiver characteristics and caregiver outcomes at home and in institutionalised long-term care (ILTC)

\begin{tabular}{|c|c|c|c|c|c|c|c|c|c|c|}
\hline \multirow{2}{*}{ Care receiver characteristics } & \multicolumn{3}{|c|}{ Total $(n=5197)$} & \multicolumn{3}{|c|}{ At home $(n=4227)$} & \multicolumn{3}{|c|}{ ILTC $(n=920)$} & \multirow[t]{2}{*}{$p$-value } \\
\hline & & & & & & & & & & \\
\hline Socio-Demographic Characteristics & $n$ & & & $n$ & & & $n$ & & & \\
\hline Age, mean (sd) & 5197 & 80.7 & $(7.25)$ & 4227 & 79.6 & (6.9) & 920 & 85.7 & (6.5) & $<.001$ \\
\hline Female, \% & 5197 & 62 & & 4277 & 59 & & 920 & 76 & & $<.001$ \\
\hline Native, \% & 5190 & 94 & & 4271 & 93 & & 919 & 96 & & .005 \\
\hline Mean level of education & 4615 & & & 3740 & & & 875 & & & $<.001$ \\
\hline Low, \% & & 44 & & & 41 & & & 55 & & \\
\hline Middle, \% & & 51 & & & 52 & & & 43 & & \\
\hline High, \% & & 5 & & & 7 & & & 3 & & \\
\hline Marital status & 5191 & & & 4273 & & & 918 & & & $<.001$ \\
\hline Married/cohabiting, \% & & 48 & & & 54 & & & 20 & & \\
\hline Widowed/divorced/single, \% & & 52 & & & 46 & & & 80 & & \\
\hline Health-Related Characteristics & $\mathrm{n}$ & & & n & & & $\mathrm{n}$ & & & \\
\hline Number of morbidities, mean $(\mathrm{sd})$, ranging from 0 to $17^{\mathrm{a}}$ & $2,142^{b}$ & 4.0 & $(2.5)$ & $1918^{b}$ & 3.9 & (2.5) & $224^{b}$ & 4.6 & (2.4) & $<.001$ \\
\hline Disability, mean (sd), ranging from $\mathbf{0}$ to $15^{\mathrm{a}}$ & $4118^{b}$ & 5.9 & (3.4) & $3344^{b}$ & 5.5 & (3.2) & $774^{b}$ & 7.8 & (3.3) & $<.001$ \\
\hline Self-perceived health, mean (sd), ranging from 1 to $\mathbf{5}^{\text {a }}$ & $4334^{b}$ & 2.5 & (.8) & $3489^{b}$ & 2.5 & (.8) & $845^{b}$ & 2.4 & (.8) & $<.001$ \\
\hline Psychological wellbeing, mean (sd), ranging from 5 to $30^{\text {a }}$ & $4096^{b}$ & 22.6 & $(4.3)$ & $3303^{b}$ & 22.7 & $(4.2)$ & $793^{b}$ & 22.4 & $(4.7)$ & .080 \\
\hline Caregiver characteristics & & & & & & & & & & \\
\hline Socio-Demographic Characteristics & $\mathrm{n}$ & & & n & & & $\mathrm{n}$ & & & \\
\hline Age, mean (sd) & $4563^{b}$ & 63.2 & $(12.5)$ & $3680^{b}$ & 64.0 & (12.9) & $883^{b}$ & 60.1 & (10.4) & $<.001$ \\
\hline Female, \% & 4081 & 69 & & 3201 & 69 & & 880 & 71 & & .188 \\
\hline Relationship with care receiver & 5141 & & & 4235 & & & 906 & & & $<.001$ \\
\hline Child (in law), \% & & 51 & & & 46 & & & 75 & & \\
\hline Partner, \% & & 39 & & & 46 & & & 10 & & \\
\hline Others, \% & & 10 & & & 8 & & & 15 & & \\
\hline Living together with care receiver, \% & 5154 & 51 & & 4239 & 50 & & 915 & 6 & & $<.001$ \\
\hline Health-Related Characteristics & $\mathrm{n}$ & & & n & & & $n$ & & & \\
\hline Self-perceived health, mean (sd), ranging from 1 to $5^{\text {a }}$ & $5050^{b}$ & 3.1 & $(1.0)$ & $4148^{b}$ & 3.1 & $(1.0)$ & $902^{b}$ & 3.2 & $(1.0)$ & $<.001$ \\
\hline Caregiving-Related Characteristics & $\mathrm{n}$ & & & $\mathrm{n}$ & & & $\mathrm{n}$ & & & \\
\hline Objective burden, mean (sd), ranging from 0 to $168 \mathrm{~h}$ & $3950^{b}$ & 17.4 & $(24.2)$ & $3168^{b}$ & 19.2 & $(25.5)$ & $782^{b}$ & 9.0 & (14.0) & $<.001$ \\
\hline Tasks around the house (e.g., cleaning, preparing meals) & & 9.9 & $(16.3)$ & & 11.2 & $(17.3)$ & & 4.0 & (8.1) & \\
\hline Personal care (e.g., dressing or eating) & & 3.7 & (9.4) & & 3.8 & $(10.2)$ & & 1.5 & (4.9) & \\
\hline Assistance with other activities (e.g., travelling, financial matters) & & 4.7 & $(8.5)$ & & 4.9 & (9.1) & & 3.5 & (4.9) & \\
\hline Variation in caregiving tasks & $3950^{b}$ & & & $3168^{b}$ & & & $782^{b}$ & & & $<.001$ \\
\hline$<2$ tasks, $\%$ & & 32 & & & 31 & & & 39 & & \\
\hline$\geq 2$ tasks, $\%$ & & 68 & & & 69 & & & 61 & & \\
\hline Hours support per week, mean (sd) ranging from 0 to $168 \mathrm{~h}$ & $3950^{b}$ & 2.9 & $(7.8)$ & $3168^{b}$ & 3.0 & $(8.3)$ & $782^{b}$ & 2.3 & $(5.2)$ & .032 \\
\hline Caregiver outcomes & n & & & $n$ & & & $\mathrm{n}$ & & & \\
\hline Subjective burden, mean (sd), ranging from $\mathbf{0}$ to $100^{a}$ & $4746^{b}$ & 41.9 & $(25.0)$ & $3870^{b}$ & 42.2 & $(25.2)$ & $876^{b}$ & 40.1 & $(24.2)$ & .134 \\
\hline Quality of life mean (sd), ranging $0-100^{a}$ & $4074^{b}$ & 79.6 & $(15.0)$ & $3287^{b}$ & 78.9 & (15.1) & $787^{b}$ & 82.7 & (14.0) & 0.014 \\
\hline
\end{tabular}

Significant results $(p<0.05)$ are in bold

${ }^{a}$ bold scores are most favourable scores

${ }^{b}$ missing values imputed by multiple imputation 
health $(\beta=-2.990)$ and psychological well-being $(B=-.860)$ of the care receiver. With regard to the caregiver characteristics, being female ( 40.515 vs. 35.768$)$, being the partner (40.534) and living together with the care receiver ( 40.323 vs. 38.722 ) was significantly associated with more subjective burden. In addition, the subjective burden decreased with better self-perceived health $(B=-5.868)$ of the caregiver and increased with more caregiving hours $(\beta=.224)$, more variation in caregiving tasks (42.811 vs. 31.994) and more support hours $(\beta=.157)$. Details are displayed in Table 2.

Informal caregivers experienced a significantly higher care-related quality of life, if the care receiver was older $(B=.174)$, female (81.936 vs. 77.394$)$ and widowed/divorced/single (82.051 vs. 78.089). In addition, caregivers' quality of life decreased with more morbidities $(ß=-.588)$ and higher levels of disability $(\beta=-.240)$ and increased with better self-perceived health $(B=1.549)$ and psychological well-being $(\beta=.391)$ of the care receiver. With regard to the caregiver characteristics, being younger $(ß=-.121)$ and being male ( 83.035 vs. 79.982$)$ was significantly associated with higher care-related quality of life. In contrast, being the partners and living together (77.360 vs. 82.337) with the care receiver decreased the caregivers' quality of life. In addition, care-related quality of life increased with better self-perceived health $(\beta=6.063)$ and decreased with more caregiving hours $(B=-.105)$ and more variation in caregiving tasks (79.268 vs. 82.329$)$. Details are displayed in Table 2.

\section{Moderating effect of the setting (at home vs. ILTC) on these associations}

The results, with regard to the moderating effect of the setting (at home vs. ILTC) on the associations between care receiver/caregiver characteristics and caregiver outcomes, are presented in Table 3. While the increasing age of the care receiver at home is associated with an increasing subjective burden $(\beta=.146)$, it was the other way around in ILTC $(\beta=-.192)$. Furthermore, when comparing both settings, the caregivers' subjective burden at home increased sharply with the increasing disability of the care receiver $(\beta=1.946$ vs. $\beta=1.068)$ and there was more variation in caregiving tasks than in ILTC (at home: 31.142 vs. 42.861; ILTC: 35.763 vs. 42.939). Also, the positive association between caregivers' self-perceived health and care-related quality of life is stronger in caregivers caring for a care receiver at home compared to caregivers in ILTC ( $\beta=6.305$ vs. $ß=4.939)$.

\section{Discussion}

With regard to the first study objective, our study showed that care receivers at home were younger and in better health than care receivers in ILTC. However, both groups of care receivers reported a similar level of psychological wellbeing. Consequently, admission to an ILTC facility does not necessarily reduces the well-being of care receivers. This is line with the study of Beerens et al. [27] that showed that care receivers' quality of life is comparable at home and in ILTC. Furthermore, our study showed that caregivers in ILTC experienced lower objective burden compared to caregivers at home. However, caregivers in ILTC still delivered a considerable number of caregiving hours (on average $9 \mathrm{~h}$ /week), which contributes to the evidence that informal caregiving often continues after admission to an ILTC $[8,9]$. This is in line with previous studies $[6,8,9]$ that have shown that caregivers in ILTC still experience high levels of subjective burden. Consequently, it is understandable that ILTC caregivers in our study experienced a comparable subjective burden to caregivers at home, even though they devote significantly less time to their caregiving tasks. Our study also indicated that caregivers' care-related quality of life was somewhat lower at home compared to ILTC, which may be due to the fact that caregivers at home were mostly caring for either their parents or their partner. In contrast, in ILTC most caregivers were caring for their parents and were consequently younger and in better health. However, it is a remarkable finding that caregivers in both settings experienced relatively high levels of care-related quality of life despite their burden $[3,28]$. Obviously, positive experiences may act as a buffer against the stress-related consequences of informal caregiving [4]. Nevertheless, it is important to engage, educate and support informal caregivers, as they are more likely to experience poor health and decreased wellbeing than non-caregivers [29-31]. This is especially true when their caregiving tasks exceed their psychological and social resources to cope with the care needs of the care receiver [4].

With regard to the second study objective, several significant associations were found between care receiver/ caregiver characteristics and caregiver outcomes. Higher subjective burden and lower care-related quality of life in caregivers were associated with the following care receiver characteristics: being male, married/cohabiting, and poor health-related characteristics. In addition, caregivers experienced an increased subjective burden and a decrease in care-related quality of life, if they were female, lived together with the care receiver, had higher objective burden and lower self-perceived health. These risk factors are in line with previous research [32]. In addition, support from other informal caregivers or volunteers was associated with higher subjective burden. Obviously, support is an indicator for a burdensome caregiving situation. Increasing professionals' awareness regarding informal caregivers' risks and providing them with tools and information to adequately support and 
Table 2 Association between care receiver/ caregiver characteristics and caregivers' subjective burden and care-related quality of life

\begin{tabular}{|c|c|c|c|c|c|c|c|c|}
\hline & \multicolumn{4}{|c|}{ SUBJECTIVE BURDEN } & \multicolumn{4}{|c|}{ QUALITY OF LIFE } \\
\hline & intercept & (se) & beta & (se) & intercept & (se) & beta & (se) \\
\hline \multicolumn{9}{|l|}{ Care receiver characteristics } \\
\hline \multicolumn{9}{|l|}{ Socio-demographic characteristics } \\
\hline Age & 31.535 & 4.306 & .098 & .050 & 66.173 & 3.473 & .174 & .033 \\
\hline \multicolumn{9}{|l|}{ Sex } \\
\hline Male & 40.736 & 1.578 & -2.096 & .713 & 77.394 & 1.718 & 4.542 & .616 \\
\hline Female & 38.641 & 1.536 & 2.096 & .713 & 81.936 & 1.330 & -4.542 & .616 \\
\hline \multicolumn{9}{|l|}{ Ethnicity } \\
\hline Native & 39.301 & 1.519 & 1.870 & 1.419 & 80.290 & 1.492 & -1.263 & .897 \\
\hline Non-native & 41.171 & 2.021 & -1.870 & 1.419 & 79.026 & 1.466 & 1.264 & .897 \\
\hline \multicolumn{9}{|l|}{ Education } \\
\hline Low vs. middle & 39.158 & 1.541 & .038 & .768 & 80.540 & 1.587 & -.384 & .438 \\
\hline Middle vs. high & 39.197 & 1.525 & 1.067 & 1.632 & 80.156 & 1.579 & -.556 & .934 \\
\hline High vs. low & 40.263 & 2.104 & -1.105 & 1.653 & 79.600 & 1.729 & .940 & .944 \\
\hline \multicolumn{9}{|l|}{ Marital status } \\
\hline Married/cohabiting & 40.283 & 1.574 & -1.551 & .705 & 78.089 & 1.637 & 3.962 & .538 \\
\hline Widowed/divorced/single & 38.733 & 1.559 & 1.551 & .705 & 82.051 & 1.362 & -3.962 & .538 \\
\hline \multicolumn{9}{|l|}{ Health-related characteristics } \\
\hline Number of morbidities, ranging from $0-17^{a}$ & 35.132 & 1.686 & 1.090 & .206 & 82.555 & 1.691 & -.588 & .140 \\
\hline Disability, ranging from $\mathbf{0}$ to $15^{\mathrm{a}}$ & 30.297 & 1.435 & 1.678 & .106 & 81.543 & 1.852 & -.240 & .097 \\
\hline Self-perceived health, ranging from 1 to $\mathbf{5}^{\mathrm{a}}$ & 46.662 & 1.869 & -2.990 & .427 & 76.486 & 1.447 & 1.549 & .270 \\
\hline Psychological wellbeing, ranging from 5 to $30^{a}$ & 58.879 & 2.366 & -.860 & .081 & 71.403 & 1.628 & .391 & .051 \\
\hline \multicolumn{9}{|l|}{ Caregiver characteristics } \\
\hline \multicolumn{9}{|l|}{ Socio-demographic characteristics } \\
\hline Age & 40.519 & 2.596 & -.014 & .031 & 88.353 & 1.435 & -.121 & .025 \\
\hline \multicolumn{9}{|l|}{ Sex } \\
\hline Male & 35.768 & 1.804 & 4.747 & .829 & 83.035 & 1.164 & -3.053 & .507 \\
\hline Female & 40.515 & 1.732 & -4.747 & .829 & 79.982 & 1.102 & 3.053 & .507 \\
\hline \multicolumn{9}{|l|}{ Relationship with care receiver } \\
\hline Child vs. partner & 39.409 & 1.557 & 1.124 & .767 & 82.036 & 1.284 & -5.210 & .712 \\
\hline Partner vs. others & 40.534 & 1.579 & -4.856 & 1.257 & 76.825 & 1.741 & 6.165 & .752 \\
\hline Others vs. child & 35.678 & 1.848 & 3.731 & 1.251 & 82.991 & 1.649 & -.955 & .772 \\
\hline \multicolumn{9}{|l|}{ Living situation } \\
\hline Living together & 40.323 & 1.591 & -1.602 & .737 & 77.360 & 4.676 & 4.977 & .606 \\
\hline Not living together & 38.722 & 1.568 & 1.602 & .737 & 82.337 & 1.330 & -4.977 & .606 \\
\hline \multicolumn{9}{|l|}{ Health-Related Characteristics } \\
\hline Self-perceived health, ranging from 1 to $\mathbf{5}^{\mathrm{a}}$ & 57.466 & 1.863 & -5.868 & .354 & 61.606 & 1.458 & 6.063 & .229 \\
\hline \multicolumn{9}{|l|}{ Caregiving-Related Characteristics } \\
\hline Objective burden, ranging from 0 to 168 & 35.821 & 1.435 & .224 & .015 & 81.925 & 1.235 & -.105 & .019 \\
\hline \multicolumn{9}{|l|}{ Variation in caregiving tasks } \\
\hline$<2$ tasks & 31.994 & 1.515 & 10.818 & .731 & 82.329 & 1.147 & -3.061 & .797 \\
\hline$\geq 2$ tasks & 42.811 & 1.441 & -10.818 & .731 & 79.268 & 1.638 & 3.061 & .797 \\
\hline Support (hours), ranging from 0 to 168 & 39.005 & 1.502 & .157 & .046 & 80.144 & 1.410 & .031 & .040 \\
\hline
\end{tabular}


Table 3 Significant interaction effects between with regard to caregivers' subjective burden and care-related quality of life

\begin{tabular}{|c|c|c|c|c|c|c|c|c|}
\hline & \multicolumn{4}{|c|}{ SUBJECTIVE BURDEN } & \multicolumn{4}{|c|}{ QUALITY OF LIFE } \\
\hline & intercept & (se) & beta & (se) & intercept & (se) & beta & (se) \\
\hline \multicolumn{9}{|l|}{ Care receiver characteristics } \\
\hline \multicolumn{9}{|l|}{ Socio-demographic characteristics } \\
\hline Age, institutionalised long-term care & 56.633 & $(11.125)$ & -.192 & $(.130)$ & & & & \\
\hline Age, at home & 27.567 & $(4.763)$ & .146 & $(.056)$ & & & & \\
\hline \multicolumn{9}{|l|}{ Health-Related Characteristics } \\
\hline Disability (ranging from $\mathbf{0}$ to $15^{\mathrm{a}}$ ) institutionalised long-term care & 32.034 & $(2.596)$ & 1.068 & $(.245)$ & & & & \\
\hline Disability (ranging from $\mathbf{0}$ to 15 a), at home & 29.517 & $(1.433)$ & 1.946 & $(.121)$ & & & & \\
\hline \multicolumn{9}{|l|}{ Caregiver characteristics } \\
\hline \multicolumn{9}{|l|}{ Health-Related Characteristics } \\
\hline Self-perceived health (ranging from 1 to $\mathbf{5}^{\mathrm{a}}$ ), institutionalised long-term care & & & & & 66.226 & $(2.207)$ & 4.939 & $(.462)$ \\
\hline Self-perceived health (ranging from 1 to $\mathbf{5}^{\mathrm{a}}$ ), at home & & & & & 60.653 & $(1.433)$ & 6.305 & $(.267)$ \\
\hline \multicolumn{9}{|l|}{ Caregiving-Related Characteristics } \\
\hline$<2$ tasks, institutionalised long-term care & 35.763 & $(2.029)$ & 7.175 & $(1.654)$ & & & & \\
\hline$\geq 2$ tasks, institutionalised long-term care & 42.939 & $(1.875)$ & -7.175 & $(1.654)$ & & & & \\
\hline$<2$ tasks, at home & 31.142 & $(1.546)$ & 11.719 & $(.813)$ & & & & \\
\hline$\geq 2$ tasks, at home & 42.861 & $(1.455)$ & -11.719 & $(.813)$ & & & & \\
\hline
\end{tabular}

Only significant interaction terms $(p<0.05)$ are displayed

${ }^{a}$ bold scores are most favourable scores

involve them in care delivery is highly important to adequately engage, educate and support informal caregivers [4] so that they can persevere in their caregiving task for longer [3].

With regard to the third study objective, our study showed that whereas the subjective burden increased with the care receivers' age at home, it decreased with age in ILTC. This is maybe due to the fact that informal caregivers in ILTC experience more support from professional caregivers, who take over the more challenging, intensive, and essential caregiving tasks, while informal caregivers provide voluntary, less intensive and less onerous help [33]. Furthermore, analyses have shown that higher levels of disability of the care receiver and more variation in caregiving tasks had more impact at home on subjective burden than in ILTC. Also the association between lower levels of caregivers' self-perceived health and lower care-related quality of life is stronger at home than in ILTC. This is maybe due to the fact that informal caregivers at home might not feel capable anymore to care for the care receiver [34], while informal caregivers in ILTC receive support from professional caregivers [33].

\section{Strengths and limitations}

Although many informal caregiving studies exist the strength of this study is the large data set of dyads. Furthermore, data from care receivers and caregivers in two long-term care settings (i.e., at home and in ILTC) are collected using the same outcome measures. However, some limitations of our study must be acknowledged as well. First, the care receivers and caregivers in the TOPICS-MDS database showed some variation regarding sampling frame, inclusion criteria, study design, sample size, and data collection method. This variation may influence the generalisability of the results. Nonetheless, these pooled data probably reflect reality better than data from a single project. Secondly, although a definition was provided by the TOPICS-MDS research group for the identification of informal caregivers, only 16 out of 25 studies made use of this definition. Consequently, it is not clear whether the informal caregivers of the other studies are fully comparable with the sample of these 16 studies. Thirdly, a further limitation of this study is the relatively high nonresponse on some items (see Table 1). Nevertheless, robustness checks without imputed missing values did not alter the conclusions (results not displayed). Fourthly, the TOPICS-MDS database was not specifically designed for the specific aims of this study. Consequently, operationalization of some variables was pragmatic and some relevant variables might have been missed. For example, data about other caregiver responsibilities (e.g., household chores, employment) or adaptive resources (e.g., coping behaviour, finances) were not assessed in the TOPICS-MDS. Finally, this study is based on cross-sectional data and the results have to be interpreted with caution, as no causal relationship can be proven. 
In conclusion, this study provides insight into the objective and subjective burden and care-related quality of life of informal caregivers - at home and in ILTC. While a substantial number of studies have been conducted among community-dwelling older adults and their informal caregivers, little was known about informal care in ILTC, especially with regard to caregiving hours provided (objective burden). The direct comparison between the two settings is also novel. Furthermore, this study showed that despite significantly less caregiving hours in ILTC, caregivers in ILTC experienced a comparable level of subjective burden to caregivers at home. This finding implies that a reduction in objective burden resulting from an admission to an ILTC facility does not necessarily have to lead towards a relief of subjective caregiving burden. However, this study has also shown that informal caregivers at home are still most at risk of experiencing higher subjective burden and lower carerelated quality of life than caregivers in ILTC.

\section{Implications}

This study results in several implications for policy and practice:

(1) Policy makers and professional caregivers have to take into account that caregiving does not stop with admission to an ILTC facility. Consequently, both settings need an informal caregiving policy that facilitates complementary service delivery, which is tailored to the individual needs and preferences of care receivers and informal caregivers. Consequently, it is essential that professional caregivers assess these needs and evaluate the provided services on a regular base. It is likely that care receiver and caregiver needs are different at home care and in ILTC due to their individual characteristics. For example, this study has shown that caregivers at home often care for their partner. In contrast, in ILTC most caregivers were caring for their parents. It is obvious that children have other needs than partners due to differences in age, health status and additional responsibilities (e.g., employment). Furthermore, admission to an ILTC facility also leads towards a shift in caregiver tasks and responsibilities. However, it is not clear whether these tasks are expected by professional caregivers or whether informal caregivers by themselves feel obligated to participate in these tasks. It is important that professional and informal caregivers exchange their expectations regarding these tasks and responsibilities to avoid an increase in subjective burden and a decrease in care-related quality of life.

(2)In this study, several significant associations were found between care receiver/caregiver characteristics and caregiver outcomes. Higher subjective burden and lower care-related quality of life in caregivers were associated with the following care receiver characteristics: being male, married/cohabiting, and poor health-related characteristics. In addition, caregivers experienced an increased subjective burden and a decrease in care-related quality of life, if they were female, lived together with the care receiver, had higher objective burden and lower self-perceived health and received support from other informal caregivers or volunteers was associated with higher subjective burden. Some of these associations were stronger for dyads at home compared to dyads in ILTC. Professional caregivers should pay special attention to these groups of informal caregivers, for example by assessing these (and eventual other) risk factors to eventually offer proactive interventions (e.g., psychological or social support) to reduce or even prevent these outcomes. Furthermore, at home professional caregivers may have an important role in monitoring and discussing the need for an ILTC admission.

(3)Despite their objective and subjective burden, caregivers in both settings experienced relatively high levels of care-related quality of life. Obviously, positive experiences may act as a buffer against the stress-related consequences of informal caregiving. A more balanced perspective on informal caregiving is suggested, which aims to reduce the negative outcomes and emphasise the positive outcomes at the same time. Consequently, professional caregiver should stimulate informal caregivers to reflect on their positive experiences with being a caregiver. In addition, it is important to acknowledge their efforts by giving them compliments for their executed caregiving tasks.

\section{Conclusion}

This study contributes to the evidence that Informal caregiving does not stop with admission to an ILTC facility. Caregivers in both settings experienced high burden, and caregivers in ILTC still delivered a considerable number of caregiving hours. Several care receiver/caregiver characteristics were identified who were associated with an increase in burden and/or a decrease in carerelated quality of life. Some of these associations were stronger for dyads at home compared to dyads in ILTC indicating a higher risk for this subgroup. To support caregivers in their caregiving tasks both settings need an informal caregiving policy, which is (1) tailored to the individual characteristics of care receivers and caregivers; (2) pays attention to the identified risk groups; and (3) reduces the negative caregiver outcomes and emphasizes the positive outcomes at the same time. 


\section{Additional files}

Additional file 1: Background information included studies. ${ }^{a}$ The TOPICS-MDS research group provided the following definition of informal caregivers: those who deliver, voluntarily and unpaid on a structural basis, care for people with physical, mental or psychological limitations in their family, household or social network because the care-receivers' health prohibits them from doing certain things themselves. (DOCX $50 \mathrm{~kb}$ )

Additional file 2: Background information about TOPICS-MDS questionnaire. ${ }^{a}$ Only items that were relevant for this study are displayed. (DOCX $45 \mathrm{~kb})$

\section{Abbreviations}

ILTC: institutionalised long-term care; SPSS: Statistical package for the socia sciences; TOPICS-MDS: The Older Persons and Informal Caregivers Survey Minimum DataSet

\section{Acknowledgements}

The authors would like to thank the TOPICS-MDS data managers, and their research assistant Floor Koomen for their support with handling the data.

\section{Funding}

This work was supported by the Dutch National Care for the Elderly Program by the Netherlands Organization for Health Research and Development [grant number 633400001]. The funding body had no role in the design of the study and collection, analysis, and interpretation of data and in writing the manuscript.

\section{Availability of data and materials}

The data that support the findings of this study are available from TOPICSMDS database (http://topics-mds.eu/) or from the authors upon reasonable request and with permission of the national TOPICS-MDS group.

\section{Authors' contributions}

$\mathrm{SM}, \mathrm{EV}, \mathrm{MV}$, JVE and GK made substantial contributions to conception and design of the study. All authors (SM, EV, MV, JvE, AA, GK) were involved in the analysis and interpretation of the data; SM draft the first version of the manuscript. All co-authors (EV, MV, JVE, AA, GK) were involved in revising it critically for important intellectual content. All authors (SM, EV, MV, JVE, AA, GK) gave final approval of the version to be published and participated sufficiently in the work to take public responsibility for appropriate portions of the content. They also agreed to be accountable for all aspects of the work in ensuring that questions related to the accuracy or integrity of any part of the work are appropriately investigated and resolved.

\section{Ethics approval and consent to participate}

This study made use of the TOPICS-MDS database (www.topics-mds.eu). TOPICS-MDS is a public data repository which contains information on the physical and mental health and wellbeing of older persons and informal caregivers across the Netherlands. To access data potential users have to complete a TOPICS-MDS Data Request Form. Following submission, requests will be assessed by TOPICS Project Group for feasibility and overlap with previous or on-going data requests. To avoid preferential release of data, requests will also be review by TOPICS Societal Board, which focuses on societal relevance of the research question. The data of the TOPICS-MDS database is de-identified and available for public access. Therefore, research which is conducted using TOPICS-MDS fall outside the scope of the Dutch Medical Research Involving Human Subjects Act (WMO).

\section{Consent for publication}

Not applicable.

\section{Competing interests}

The authors declare that they have no competing interests.

\section{Publisher's Note}

Springer Nature remains neutral with regard to jurisdictional claims in published maps and institutional affiliations.

\section{Author details}

'Department of Health Services Research, Faculty of Health, Medicine and Life Sciences, Care and Public Health Research Institute (CAPHRI), Maastricht University, P.O. Box 616, 6200 MD Maastricht, Netherlands. ²Department of Sociology, Radboud University, P.O. Box 9104, 6500 HE Nijmegen, Netherlands. ${ }^{3}$ Huis voor de Zorg, P.O. Box 5185, 6130 PD Sittard, Netherlands. ${ }^{4}$ Erasmus School of Health Policy \& Management, Erasmus University, P.O. Box 1738, 3000 DR Rotterdam, Netherlands. ${ }^{5}$ Department of Methodology and Statistics, Faculty of Health, Medicine and Life Sciences, CAPHRI School for Public Health and Primary Care, Maastricht University, P.O. Box 616, 6200 MD Maastricht, Netherlands.

Received: 16 September 2016 Accepted: 2 October 2017 Published online: 10 October 2017

\section{References}

1. Tappenden P, Campbell F, Rawdin A, Wong R, Kalita N. The clinical effectiveness and cost-effectiveness of home-based nurse-led health promotion for older people: a systematic review. Health Technol Assess. 2012:16(20):1-72.

2. Verbeek-Oudijk D, Woittiez I, Eggink E, Putman L. Who cares in Europe? A comparison of long-term care for the over-50s in sixteen European countries. The Hague: The Netherlands Institute for Social Research; 2014.

3. Kraijo H, Brouwer W, de Leeuw R, Schrijvers $G$, van Exel J. The perseverance time of informal carers of dementia patients: validation of a new measure to initiate transition of care at home to nursing home care. J Alzheimers Dis. 2014;40(3):631-42.

4. Roth DL, Fredman L, Haley WE. Informal Caregiving and its impact on health: a reappraisal from population-based studies. Gerontologist. 2015; 55(2):309-19.

5. Colombo F, Llena-Nozal A, Mercier J, Tjadens F. Help wanted? Providing and paying for long-term care. Paris: OECD; 2011.

6. Broese van Groenou M. Mantelzorg in het tehuis. TSG. 2010;88(6):329-35.

7. Whitlatch CJ, Schur D, Noelker LS, Ejaz FK, Looman WJ. The stress process of family caregiving in institutional settings. Gerontologist. 2001:41(4):462-73.

8. Schulz R, Rosen J, Klinger J, Musa D, Castle NG, Kane A, Lustig A. Effects of a psychosocial intervention on caregivers of recently placed nursing home residents: a randomized controlled trial. Clin Gerontol. 2014;37(4):347-67.

9. ActiZ Expertisecentrum Informele Zorg. Samenspel met mantelzorg. Utrecht: Organisatie voor zorgondernemers; 2007.

10. Brouwer WB, van Exel NJ, van den Berg B, van den Bos GA, Koopmanschap MA. Process utility from providing informal care: the benefit of caring. Health Policy. 2005;74(1):85-99.

11. Al-Janabi H, Frew E, Brouwer W, Rappange D, Van Exel J. The inclusion of positive aspects of caring in the caregiver strain index: tests of feasibility and validity. Int J Nurs Stud. 2010:47(8):984-93.

12. De Boer A, Broese van Groenou MI, Timmermans JT. Mantelzorg. Een overzicht van de steun van en aan mantelzorgers in 2007. The Hague: SCP; 2009.

13. Carbonneau H, Caron C, Desrosiers J. Development of a conceptual framework of positive aspects of caregiving in dementia. Dementia. 2010; 9(3):327-53.

14. De Boer A, de Klerk M. Informele zorg in Nederland; een literatuurstudie naar mantelzorg en vrijwilligerswerk in de zorg. The Hague: SCP; 2013.

15. Cuijpers M, Kruijswijk W, van Lier W. Momenten van zin. Essay over zingeving en mantelzorg. Utrecht: Expertisecentrum Mantelzorg; 2012.

16. Lutomski JE, Baars MAE, Schalk BWM, Boter $H$, Buurman BM, den Elzen WPJ, Jansen APD, Kempen GIJM, Steunenberg B, Steyerberg EW, et al. The development of the older persons and informal caregivers survey minimum DataSet (TOPICS-MDS): a large-scale data sharing initiative. PLoS One. 2013; 8(12):e81673.

17. Katz S, Ford AB, Moskowitz RW, Jackson BA, Jaffe MW. Studies of illness in the aged: the index of ADL: a standardized measure of biological and psychosocial function. JAMA. 1963;185(12):914-9.

18. Lawton MP, Brody EM. Assessment of older people: self-maintaining and instrumental activities of daily living. Gerontologist. 1969:9:179-86.

19. Van der Zee K, Sanderman R. Het meten van de algemene gezondheidstoestand met de Rand-36: een handleiding. NCG: Groningen; 2012

20. Hoefman RJ, NJA VE, WBF B. iMTA valuation of informal care questionnaire (iVICQ). Version 1.0 (December 2011). Rotterdam: iBMG / iMTA. p. 2011. 
21. Van Exel NJ, Scholte op Reimer WJ, Brouwer WB, van den Berg B, Koopmanschap MA, van den Bos GA. Instruments for assessing the burden of informal caregiving for stroke patients in clinical practice: a comparison of CSI, CRA, SCQ and self-rated burden. Clin Rehabil. 2004;18(2):203-14.

22. Lutomski JE, van Exel NJA, Kempen GIJM, Moll van Charante EP, den Elzen WPJ, Jansen APD, Krabbe PFM, Steunenberg B, Steyerberg EW, Olde Rikkert MGM, et al. Validation of the care-related quality of life instrument in different study settings: findings from the older persons and informal caregivers minimum DataSet (TOPICS-MDS). Qual Life Res. 2015;24:1281-93.

23. Brouwer WB, van Exel NJ, van Gorp B, Redekop WK. The CarerQol instrument: a new instrument to measure care-related quality of life of informal caregivers for use in economic evaluations. Qual Life Res. 2006; 15(6):1005-21.

24. Hoefman RJ, van Exel NJ, Foets M, Brouwer WB. Sustained informal care: the feasibility, construct validity and test-retest reliability of the CarerQol-instrument to measure the impact of informal care in long-term care. Aging Ment Health. 2011;15(8):1018-27.

25. Hoefman RJ, van Exel NJ, Looren de Jong S, Redekop WK, Brouwer WB. A new test of the construct validity of the CarerQol instrument: measuring the impact of informal care giving. Qual Life Res. 2011;20(6):875-87.

26. Hoefman RJ, van Exel J, Brouwer W. How to include informal care in economic evaluations. PharmacoEconomics. 2013:31(12):1105-19.

27. Beerens HC, Sutcliffe C, Renom-Guiteras A, Soto ME, Suhonen R, Zabalegui A, Bökberg C, Saks K, Hamers JP. Quality of life and quality of care for people with dementia receiving long term institutional care or professional home care: the European RightTimePlaceCare study. J Am Med Dir Assoc. 2014;15(1):54-61

28. Hoefman RJ, van Exel J, Brouwer WB. Measuring the impact of caregiving on informal carers: a construct validation study of the CarerQol instrument. Health Qual Life Outcomes. 2013;11(173):1-13.

29. Pinquart M, Sörensen S. Differences between caregivers and noncaregivers in psychological health and physical health: a meta-analysis. Psychol Aging. 2003:18(2):250-67.

30. Bobinac A, van Exel NJ, Rutten FF, Brouwer WB. Health effects in significant others: separating family and care-giving effects. Med Decis Mak. 2011;31(2): 292-8.

31. Bobinac A, van Exel NJ, Rutten FF, Brouwer WB. Caring for and caring about: disentangling the caregiver effect and the family effect. J Health Econ. 2010; 29(4):549-56.

32. Adelman RD, Tmanova LL, Delgado D, Dion S, Lachs MS. Caregiver burden: a clinical review. JAMA. 2014;311(10):1052-60.

33. Brandt M, Haberkern K, Szydlik M. Intergenerational help and Care in Europe. Europ Sociol Rev. 2009;25(5):585-601.

34. Afram B, Stephan A, Verbeek H, Bleijlevens MH, Suhonen R, Sutcliffe C, Raamat K, Cabrera E, Soto ME, Hallberg IR, et al. Reasons for institutionalization of people with dementia: informal caregiver reports from 8 European countries. J Am Med Dir Assoc. 2014;15(2):108-16.

\section{Submit your next manuscript to BioMed Central and we will help you at every step:}

- We accept pre-submission inquiries

- Our selector tool helps you to find the most relevant journal

- We provide round the clock customer support

- Convenient online submission

- Thorough peer review

- Inclusion in PubMed and all major indexing services

- Maximum visibility for your research

Submit your manuscript at www biomedcentral.com/submit

) Biomed Central 